\title{
A ANÁLISE DE HISTÓRIA EM QUADRINHOS DE UMA VIDEOAULA NA PERSPECTIVA DA NARRATIVA DE TELEVISÃO
}

\section{THE ANALYSIS OF COMICS OF A VIDEO LESSON IN THE PERSPECTIVE OF THE TELEVISION NARRATIVE}

\author{
Paulo Vitor Tavares, M.Sc. ${ }^{1}$ \\ Luciane Maria Fadel, DSc ${ }^{2}$ \\ Francisco Antônio Pereira Fialho, DSc ${ }^{3}$ \\ Richard Perassi Luiz de Sousa, DSc ${ }^{4}$ \\ Silvio Serafim da Luz Filho, DSc ${ }^{5}$ \\ (1) Universidade Federal de Santa Catarina - UFSC \\ tavarespv@hotmail.com \\ (2) Universidade Federal de Santa Catarina - UFSC \\ liefadel@gmail.com \\ (3) Universidade Federal de Santa Catarina - UFSC \\ fapfialho@gmail.com \\ (4) Universidade Federal de Santa Catarina-UFSC \\ richard.perassi@uol.com.br \\ (5) Universidade Federal de Santa Catarina - UFSC \\ silvioserafim@bol.com.br
}

videoaula, quadrinhos, narrativa.

Trata-se de um trabalho teórico-empírico que discute a efetividade da mensagem de história em quadrinhos em videoaula. São analisados da história em quadrinhos os aspectos conteúdo e narrativa, que influenciam nas funções referencial e emotiva. Concluiu-se que a história em quadrinhos adotou elementos narrativos que proporcionaram força estética e, consequentemente, potencializou o processamento do conhecimento.

video lesson, comics, narrative.

This is a theoretical-empirical work that discusses the effectiveness of the comic message in the video lesson. Of comics are analyzed the content and narrative aspects, which influence on the referential and emotive functions. We conclude that comics adopt narrative elements that provide aesthetic strength and, consequently, enhance the 


\section{$16^{\circ}$ \\ ERGODESIGN USIHC CINAHPA}

$16^{\circ}$ Ergodesign - Congresso Internacional de Ergonomia e Usabilidade de Interfaces Humano Tecnológica: Produto, Informações Ambientes Construídos e Transporte

$16^{\circ}$ USIHC - Congresso Internacional de Ergonomia e Usabilidade de Interfaces Humano Computador

CINAHPA | 2017 - Congresso Internacional de Ambientes Hipermídia para Aprendizagem.

processing of knowledge.

\section{Introdução}

O ensino, ofertado pela escola até recentemente, adota a sala de aula como ambiente de aprendizagem e recursos pedagógicos com quase nenhuma tecnologia - no máximo com tímidas tentativas de uso de mídias analógicas.

Atualmente, o ensino continua sendo responsabilidade da escola, porém já adotando algumas inovações como os ambientes virtuais de aprendizagem com recursos pedagógicos baseados em tecnologia da informação e comunicação, prática mais frequente na educação a distância, que dentre as diversas ferramentas pedagógicas tecnológicas disponíveis adota a videoaula produzida e veiculada com bases em conceitos da mídia digital e, em alguns casos, concebida como um programa de televisão na ótica da formulação de conteúdo e de narrativa (TAVARES, 2013, p.101).

A construção da mensagem televisiva - incluindo a mensagem da videoaula, que é composta por conteúdo e narrativa (TAVARES,2013, p.49), pressupõe a observância, por parte do emissor, de critérios para que o papel de entreter seja atingido, ou seja, que venha prender a atenção do receptor que é telespectador ou aluno (TAVARES,2013, p.98), no sentido que o processo tenha efetividade.

A teoria de comunicação traz fundamentação teórica importante para a formulação de videoaulas, na medida em que define as relações entre a mensagem e o receptor e se preocupa tanto com a inteligência quanto com a afetividade do processo Jakobson (2008). Dessa forma, possibilita o aumento da atratividade da mensagem pela estática, e consequentemente potencializando o processamento do conhecimento por parte do receptor que é o aluno exposto a essa mensagem.

Nesse contexto, esse artigo visa analisar as cenas de história em quadrinhos de uma videoaula por meio da narrativa própria da mídia televisão, pois acredita-se que a narrativa televisiva possa contribuir para o potencial narrativo da videoaula.

\section{Videoaulas da TV IFSC}

A pesquisa documental se baseou nas videoaulas produzidas pela TV IFSC, que não é uma aula presencial gravada em vídeo, mas um programa de televisão (TAVARES, 2013, p.47), contando com a participação do professor (a), apresentador (a), presença de grafismo animado, desenho animado, fotos cobrindo locução em off, enquetes, entrevistas, dentre outros tipos de cena, respeitando os princípios da construção da mensagem para essa mídia.

História em quadrinhos usa a linguagem da mídia impressa, mas, no caso das videoaulas da TV IFSC, a história em quadrinhos foi incorporada a mídia eletrônica televisão, que tem formulação própria da mensagem, tanto nos elementos conteúdo quanto narrativa.

Dentre as videoaulas produzidas pela TV IFSC foi escolhida para estudo a história em quadrinhos em vídeo "detetive" (1min26seg), que trata dos pronomes possessivos "seu e teu", e é uma das cenas da videoaula $2(15 \mathrm{~min} 35 \mathrm{seg})-\mathrm{a}$ complexidade da linguagem humana, produzida pela TV IFSC em 2009 e que faz parte da unidade curricular Comunicação, ministrada pela professora Esterzinha Gevaerd do Curso Superior de Tecnologia em Gestão Pública do IFSC, na modalidade a distância. A descrição das cenas da história em quadrinhos "detetive" será feita tendo como referência os elementos de narrativa da televisão. Tais elementos estão indicados em cada cena, junto com os textos de diálogos e narração.

\section{Análise da história em quadrinhos na}

\section{videoaula}

A formulação da mensagem da televisão adota alguns conceitos relacionados à teoria geral dos signos - a semiótica, principalmente definições da
Realização:

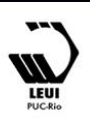




\section{$16^{\circ}$ \\ ERGODESIGN USIHC CINAHPA}

semiótica francesa. Segundo Silva (2011) a semiótica francesa, ou da Escola de Paris, é um modelo de descrição do "sentido", ou seja, uma metalinguagem, que é usada quando se deseja falar da própria linguagem usada na comunicação, portanto, compatível com a demanda de análise da história em quadrinhos inserida em uma videoaula.

"O objeto da semiótica é o "sentido"" (BERTRAND, 2003, p.11), que segundo Greimas e Courtés (1979) é apreensível pelo resultado da função semiótica da linguagem, ou seja, a reunião dos planos do conteúdo e planos da expressão, representados pela linguagem verbal, não-verbal (visual, plástica, gestual, musical etc.), ou sincrética. Assim, na análise da história em quadrinhos em estudo, inserida em uma videoaula, será usada metalinguagem como referência.

Para Greimas e Courtés (1979) Semiose é a operação de produzir signos, ao instaurar uma relação de pressuposição recíproca entre a forma da expressão (som e imagem) e a forma do conteúdo (conceito) na terminologia de L. Hjelmslev - ou, respectivamente, entre o significante e o significado, na terminologia de F. de Saussure. Semiose tem como sinônimo Significação (ou ato de significar) e se interpreta, então, quer como reunião do significante com o significado (constitutiva do signo).

Enquanto atividade cognitiva programada, a significação se acha, então, suportada e sustentada pela intencionalidade (GREIMAS e COURTÉS, 1979).

Será verificado, por meio de análise da metalinguagem, se na formulação da história em quadrinhos "detetive" ocorreu a semiose, que é, segundo Greimas e Courtés (1979) “a operação de produzir signos, ou seja, a significação efetiva com a constituição do signo em que ocorre a reunião adequada do significado (forma do conteúdo) e significante (forma da expressão) de forma intencional".

Segundo Silva (2014) a metalinguagem é usada quando a preocupação do emissor está voltada para o próprio código ou linguagem, e tem sido muito usada em busca de uma organização lúdica do $16^{\circ}$ Ergodesign - Congresso Internacional de Ergonomia e Usabilidade de Interfaces Humano Tecnológica: Produto, Informações Ambientes Construídos e Transporte

$16^{\circ}$ USIHC - Congresso Internacional de Ergonomia e Usabilidade de Interfaces Humano Computador

CINAHPA | 2017 - Congresso Internacional de Ambientes Hipermídia para Aprendizagem.
Segundo Tavares (2013, p.101) em televisão a mensagem é composta por conteúdo e narrativa: o conteúdo de TV é materializado por textos de programas de cultura, textos de programa de lazer, e textos de programas de informação. Assim, existe uma equivalência entre a definição de conteúdo da televisão com a definição de Greimas e Courtés (1979) sobre plano dos conteúdos da semiótica, que é o significado. Na narrativa da televisão estão presentes o som, ritmo e imagem. A imagem por sua vez é composta por movimentos, efeitos, cortes, planos, cor e luz (TAVARES, 2013, p.78). Aqui também existe uma equivalência entre a definição de narrativa da televisão com a definição de Greimas e Courtés (1979) sobre plano da expressão da semiótica, que é o significante.

Como o conteúdo da televisão equivale ao significado da semiótica e a narrativa da televisão equivale ao significante da semiótica, podemos afirmar que a mensagem da televisão é composta por significado e significante. Assim a mensagem da televisão equivale ao signo, que Greimas e Courtés (1979) definem na semiótica como a união entre significado e significante. Como em televisão a mensagem precisa prender a atenção do telespectador, ou seja, entreter, assim o signo tem papel de entretenimento.

Os textos destinados aos programas de televisão são transformados na mensagem por meio de narrativa adequada. A narrativa em televisão é o modo específico de se contar uma história que no vídeo tem ênfase na imagem, sendo que a palavra é um instrumento auxiliar (TAVARES, 2013, p.78).

A função referencial (cognitiva, objetiva) e a função emotiva (expressiva, subjetiva) propostas por Jakobson (2008), constituem dois polos da mesma experiência que é compreender e sentir, que caracterizam a "dupla função da linguagem". O compreender dá a capacidade de explicar e o sentir dá a capacidade de emocionar, mesmo sem a compreensão lógica dessas emoções. 


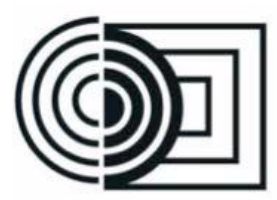

$16^{\circ}$ Ergodesign - Congresso Internacional de Ergonomia e Usabilidade de Interfaces Humano Tecnológica: Produto, Informações Ambientes Construídos e Transporte

$16^{\circ}$ USIHC - Congresso Internacional de Ergonomia e Usabilidade de Interfaces Humano Computador

CINAHPA | 2017 - Congresso Internacional de Ambientes Hipermídia para Aprendizagem.
O processo de aprender por meio de uma videoaula envolve o racional da cognição, normalmente associado ao conteúdo, e envolve o emotivo, que pode ser estimulado pela expressão ou narrativa.

O conjunto envolvendo o racional associado ao emotivo potencializa a atenção na mensagem, aumentando a possibilidade de processamento mais efetivo do conhecimento que a videoaula pretende difundir.

Greimas e Courtés (1979) indica que a análise dos signos, produzidos pela articulação da forma da expressão e forma do conteúdo, só é possível quando os dois planos da linguagem são antes dissociados para serem estudados e descritos, cada um separadamente.

Assim, passamos a analisar cada cena da história em quadrinhos "detetive" pela dissociação do plano do conteúdo (significado) e plano da expressão (significante), de modos a compreender a constituição da mensagem (signo).

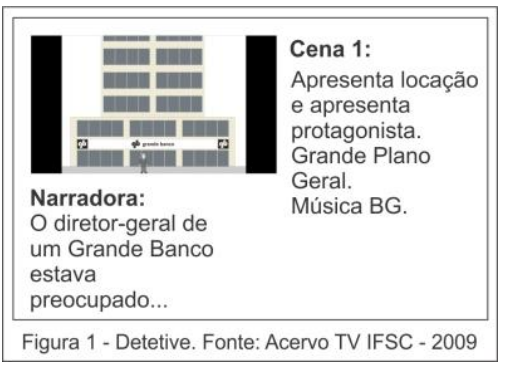

\begin{tabular}{|l|l|}
\hline & $\begin{array}{l}\text { Cena 2: } \\
\text { Apresenta } \\
\text { Antagonista } \\
\text { e evidencia a } \\
\text { marca. } \\
\text { Plano Geral. } \\
\text { Música BG. }\end{array}$ \\
\hline $\begin{array}{l}\text { Narradora: } \\
\text {...com um jovem e }\end{array}$ \\
$\begin{array}{l}\text { brilhante diretor, } \\
\text { que depois de ter } \\
\text { trabalhado } \\
\text { durante } \\
\text { algum tempo com } \\
\text { ele... }\end{array}$ \\
\hline Figura 2 - Detetive.Fonte: Acervo TV IFSC - 2009 \\
\hline
\end{tabular}
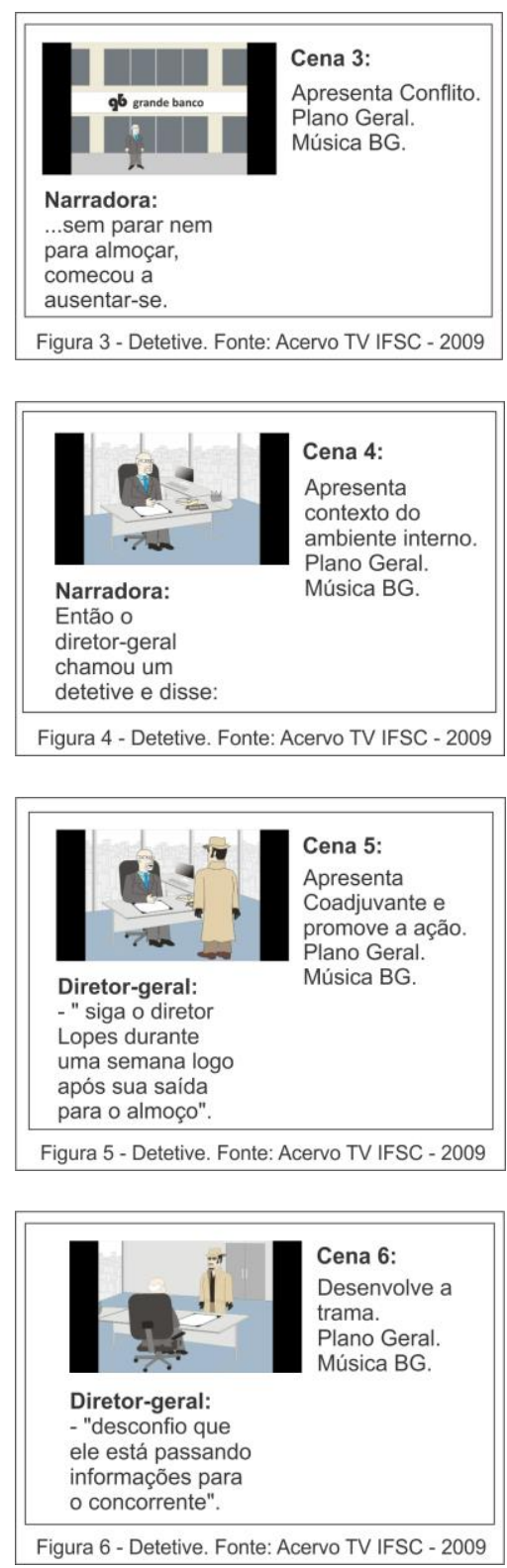

\begin{tabular}{|l|l|} 
Circulo se abre $=$ \\
passagem de \\
tempo. \\
Ambiente interno. \\
Plano Geral. \\
Música BG.
\end{tabular}

Realização:
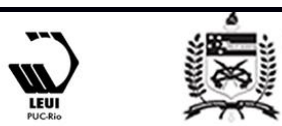


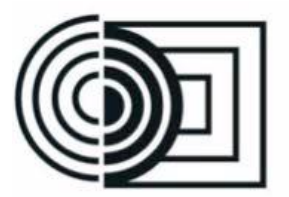

$16^{\circ}$

ERGODESIGN

USIHC CINAHPA $16^{\circ}$ Ergodesign - Congresso Internacional de Ergonomia e Usabilidade de Interfaces Humano Tecnológica: Produto, Informações Ambientes Construídos e Transporte

$16^{\circ}$ USIHC - Congresso Internacional de Ergonomia e Usabilidade de Interfaces Humano Computador

CINAHPA | 2017 - Congresso Internacional de Ambientes Hipermídia para Aprendizagem.

\begin{tabular}{|l|l|}
\hline Aena 8: \\
Apresentação de \\
Componente \\
Dramático. \\
Plano Geral. \\
sai normalmente \\
ao meio dia, pega \\
o seu carro, vai a \\
sua casa almoçar, \\
faz amor com a \\
sua mulher, fuma \\
um dos seus \\
excelentes \\
charutos cubanos \\
e regressa ao \\
trabalho. \\
Narradora: \\
Ao que o \\
diretor- geral \\
responde: \\
\hline Figura 8 - Detetive. Fonte: Acervo TV IFSC - 2009 \\
\hline
\end{tabular}

\begin{tabular}{l} 
Cena 9: \\
Ambiente interno. \\
Plano Geral. \\
Música BG. \\
- " Há bom, antes \\
assim, não há \\
nada de mal nisso! \\
Narradora: \\
Logo em seguida \\
o detetive \\
pergunta: \\
Figura 9 - Detetive. Fonte: Acervo TV IFSC - 2009 \\
\hline
\end{tabular}

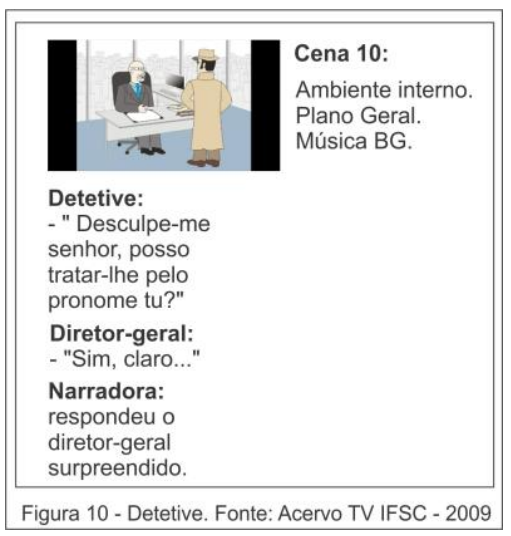

\begin{tabular}{|l|l|}
\hline Big close-up nos \\
Componentes \\
Dramáticos. \\
Detalhe na \\
plaqueta.
\end{tabular}
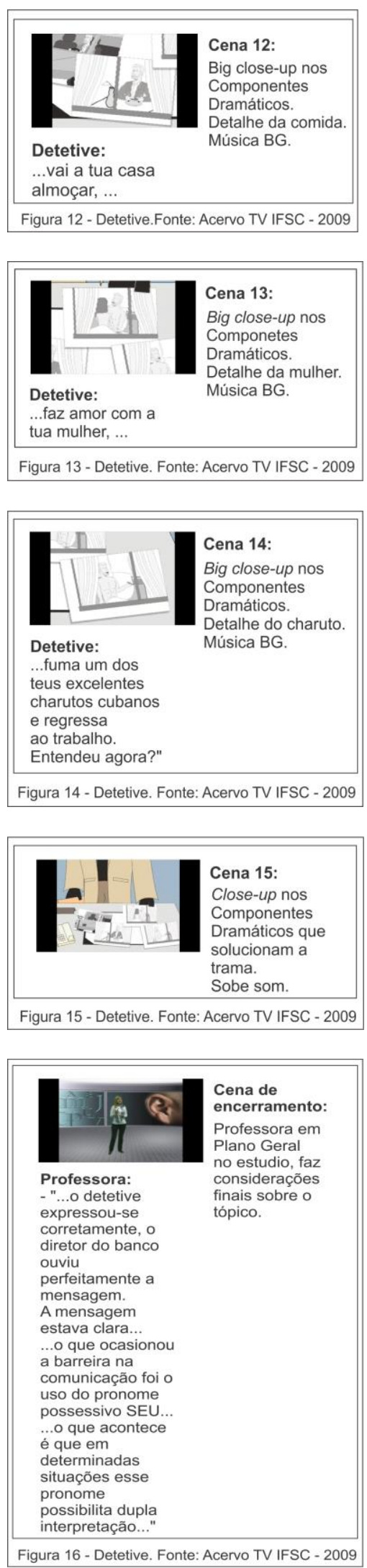

Realização:

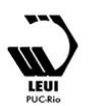


$16^{\circ}$ Ergodesign - Congresso Internacional de Ergonomia e Usabilidade de Interfaces Humano Tecnológica: Produto, Informações Ambientes Construídos e Transporte

$16^{\circ}$ USIHC - Congresso Internacional de Ergonomia e Usabilidade de Interfaces Humano Computador

CINAHPA | 2017 - Congresso Internacional de Ambientes Hipermídia para Aprendizagem.

\section{Considerações Finais}

Sendo o Signo o resultado de significado e significante, apresentamos a seguir os pontos fortes e pontos fracos do Signo em decorrência do desempenho dos indicadores de Significante e Significado:

Signo (Mensagem) - pontos fortes: entreter; surpreender; cognição; aplicação; ritmo compatível com a proposta; som ensejou suspense; humor; dramaticidade; surpresa; destaque; ausência de monotonia; luz deu tom de modernidade; cor deu tom de modernidade e sobriedade; efeito ensejou passagem de tempo; cortes compatíveis com a proposta; grandiosidade; solução; desfecho; formalidade; despojamento; dinâmica; movimentos; deslocamentos; evidências.

Signo (Mensagem) - pontos fracos: presença de narrador é mais compatível com o rádio; ausência de fusões; planos monótonos; ausência de movimentos de câmera; suspeita; subserviência; tensão; desfavorável; conflito; desconforto.

Como conclusão final podemos apontar que na história em quadrinhos "detetive", analisada a luz dos elementos da narrativa de televisão, tem um signo com força estética, pela maioria e qualidade de indicadores de pontos fortes apresentados, o que tornou a história em quadrinhos "detetive" efetiva na difusão da definição do pronome possessivo "seu e teu".

Foi possível analisar a efetividade da história em quadrinhos "detetive", a luz dos elementos da narrativa de televisão com apoio de alguns conceitos com origem na semiótica francesa.

Quanto mais intensamente forem usados os elementos narrativos que representam o significante, inclusive os emotivos, aplicados ao significado (cognitivo), mais poder estético terá o signo e maior será a possibilidade dele ser percebido, o que se traduz em maior qualidade do produto final sob o ponto de vista da atenção do telespectador. adequadamente conforme os indicadores apresentados no presente trabalho, permitindo que a história em quadrinhos virtual na videoaula, por exemplo, substitua um programa de TV do mundo real, sem a necessidade de grandes investimentos por parte do produtor /emissor individual.

Que uma videoaula com signo com força estética cumpre seu papel de difusão do conhecimento de forma atrativa.

Que o roteirista e designer da TV IFSC tiveram a preocupação com o signo dando uma organização lúdica do pensamento e um trocadilho bemhumorado para capturar a atenção do alunotelespectador ao formular a narrativa de televisão na construção da história em quadrinhos "o detetive".

Por outro lado, o tema, presente no conteúdo no ano de 2009, tratando de adultério causa certa antipatia nos dias de hoje.

\section{BIBLIOGRAFIA}

\section{BERTRAND, Denis Caminhos da semiótica literária Bauru, SP: EDUSC, 2003.}

GREIMAS, Algirdas Julien; COURTÉS, Joseph Dicionário de Semiótica 9.ed. São Paulo, SP: Cultrix, 1979.

\section{JAKOBSON, R. Linguística e comunicação} 23.ed. São Paulo, SP: Cultrix, 2008.

SILVA, Débora Metalinguagem. Disponível em <www.estudopratico.com.br/metalinguagem> (26/03/2014) acesso em: 03/03/2017.

SILVA, Fernando Moreno da Avanços da Semiótica Francesa: Estudos na Comunicação In: XII Congresso de Ciências da Comunicação na Região Sul - Intercom, Londrina - 26 a 28 de maio de 2011, Londrina/PR. Anais, São Paulo: Editora Intercom. CD-room.

TAVARES, Paulo Vitor TV e vídeo na educação 2 ed rev. - Florianópolis: IFSC, 2013.

A narrativa gera fantasia, quando trabalhada

Realização:

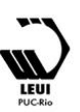

